Surgery for

Congenital

Heart Disease

\title{
Human leukocyte antigen-DR and ABO mismatch are associated with accelerated homograft valve failure in children: Implications for therapeutic interventions
}

Roger J. F. Baskett, MA, MD

Maurice A. Nanton, $M^{b}$

Andrew E. Warren, MSc, MD ${ }^{\mathrm{b}}$

David B. Ross, $\mathrm{MD}^{\mathrm{C}}$

From the Maritime Heart Centre \& Division of Cardiac Surgery, ${ }^{\text {a }}$ Department of Surgery, Dalhousie University, Halifax, Nova Scotia, Canada; Department of Cardiology, ${ }^{\text {b }}$ IWK Grace Hospital, Dalhousie University, Halifax, Nova Scotia, Canada; and the Division of Cardiac Surgery, ${ }^{\mathrm{c}}$ University of Alberta, Edmonton, Alberta, Canada.

Read at the Twenty-eighth Annual Meeting of The Western Thoracic Surgical Association, Big Sky, Mont, June 19-22, 2002.

Received for publication July 10, 2002; revisions requested Sept 3, 2002; revisions received Nov 25, 2002; accepted for publication Dec 30, 2002.

Address for reprints: Roger J. F. Baskett, MA, MD, Maritime Heart Centre, Room 2269 2nd Floor, 1796 Summer St., Halifax, Nova Scotia B3H 3A7 (E-mail: RogerBaskett@hotmail.com).

J Thorac Cardiovasc Surg 2003;126:232-9

Copyright (C) 2003 by The American Association for Thoracic Surgery

0022-5223/2003\$30.00+0

doi:10.1016/S0022-5223(03)00210-1
Objective: This study examines the incidence and factors associated with the failure of homograft valves and identifies those factors that are modifiable.

Methods: From 1990 to 2001, 96 homograft valves were implanted in the right ventricular outflow tract of 83 children (mean age $5.1 \pm 5.6$ years). Clinical and blinded serial echocardiographic follow-up was performed on all 90 valves in the 77 survivors.

Results: Eighteen homograft valves were replaced as the result of pulmonary insufficiency (3), stenosis (9), or both (6). Freedom from reoperation was $71 \%$ at 9 years (95\% confidence interval, 58\%-84\%). Forty-eight valves developed progressive pulmonary insufficiency of at least 2 grades, 26 valves developed transvalvular gradients of $50 \mathrm{~mm} \mathrm{Hg}$ or greater, and 14 of these valves were also insufficient. The freedom from echocardiographic failure (progressive pulmonary insufficiency $\geq 2$ grades or $\geq 50 \mathrm{~mm} \mathrm{Hg}$ gradient) was only $27 \%$ at 5 years $(95 \%$ confidence interval, $17 \%-37 \%$ ). In a multivariate analysis (Cox regression), use of an aortic homograft $(P=.001)$ and short antibiotic preservation time $(P=.04)$ were associated with reoperation. Younger age $(P=.01)$, ABO mismatch $(P=.04)$, and diagnosis $(P=$ $.005)$ were associated with echocardiographic failure. In the subanalysis of patients with human leukocyte antigen typing, age $(P=.002)$, aortic homograft $(P=.04)$, and human leukocyte antigen-DR mismatch $(P=.03)$ were associated with echocardiographic valve failure.

Conclusion: Many homografts rapidly become insufficient and require replacement. In our analysis of both reoperation and echocardiographic failure, several immunologic factors are consistently associated with homograft failure. Matching for human leukocyte antigen-DR, blood group, and avoiding short preservation times (thus minimizing antigenicity) offers the potential to extend the life of these valves.

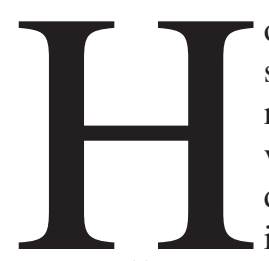

omografts in the aortic position have good longevity in adults, similar to that achieved with bioprosthetic valves. ${ }^{1,2}$ In the pulmonary position, the homograft is also a reasonably reliable valve. ${ }^{3,4}$ However, homografts are prone to early failure in children. ${ }^{5,6}$ There is mounting evidence that the valves incite an immunologic response, and that this may be associated with their failure. ${ }^{7-11}$ However, homograft valves remain the best option for valve replacement in young children. 


\section{TABLE 1. Patients with homograft valves}

\begin{tabular}{lc}
\hline Primary diagnosis & No. \\
\hline Pulmonary atresia/ventricular septal defect & 25 \\
Tetralogy of Fallot/double-outlet right ventricle & 18 \\
Complex transposition & 17 \\
Aortic stenosis (Ross procedure) & 12 \\
Truncus arteriosus & 11 \\
Total & 83
\end{tabular}

There is evidence that factors in homograft procurement and preservation, as well as homograft type and blood type, are associated with preserved immunogenicity and may be associated with valve failure. ${ }^{6,9,10}$ In vitro evidence indicates that human leukocyte antigen (HLA)-DR and ABO matching, as well as changes in preservation, can alter the immune response to cryopreserved homografts. ${ }^{12,13}$ HLA class I and II antibodies are known to be elevated in children receiving homografts, ${ }^{14}$ and it seems that HLA class II is particularly important. ${ }^{7,15}$ Despite this, it is not clear whether these factors are directly related to homograft valve failure in clinical practice. ${ }^{8,9,16,17}$

This study examines the factors associated with homograft failure in children and identifies those factors that may be modifiable.

\section{Methods}

\section{Patient Population}

Between December 1990 and May 2001 at the Izaak Walton Killam Grace Hospital, 96 consecutive cryopreserved homograft valves were implanted for right ventricular outflow tract reconstruction in 83 patients (39 female, 44 male) with a variety of congenital lesions (Table 1). The mean age at operation was 61 months \pm 67 months, (median 36 months, range 1 day-19 years). Fifty-four of the 83 patients (65\%) had undergone at least 1 previous operation. Some of the results of the first 44 of these patients have been reported. ${ }^{6}$

\section{Homograft Procurement and Preparation}

All valves were harvested en bloc under sterile conditions by a surgeon or tissue-bank technologist. The valves were incubated in $500 \mathrm{~mL}$ of Hank's balanced salt solution containing $40 \mathrm{mg}$ of gentamicin and $500 \mathrm{mg}$ of cefazolin at $4^{\circ} \mathrm{C}$ for 12 to 72 hours. The valves were cryopreserved in Hank's solution with $10 \%$ dimethylsulfoxide as a cryoprotectant. They were cooled in a controlledrate freezer (Planer KRY010, Planer Products Ltd., Sunbury-onThames, Middlesex, UK) at $1^{\circ} \mathrm{C}$ per minute to a temperature of $-80^{\circ} \mathrm{C}$ and stored in vapor phase liquid nitrogen less than $-135^{\circ} \mathrm{C}$ until used. The homografts were transported in a cooler of liquid nitrogen to the operating theater and thawed in a water bath for 10 minutes before use. Procurement and preservation times according to the protocols were as follows: warm ischemic time less than 24 hours, cold ischemic time less than 24 hours, antibiotic storage time $24 \pm 2$ hours (since 1996), and cold ischemic time and antibiotic time 30 hours or more. These times were the same
TABLE 2. Homograft valve characteristics

\begin{tabular}{|c|c|c|c|}
\hline & Mean \pm SD & Median & Range \\
\hline \multicolumn{4}{|l|}{$\begin{array}{l}\text { Sex (50 male, } 30 \text { female } \\
\text { patients) }\end{array}$} \\
\hline Tissue only donor & 51 & & \\
\hline Multiorgan donor & 23 & & \\
\hline Heart transplant recipient & 6 & & \\
\hline Age & $16.6 \pm 15.3 \mathrm{yr}$ & $13 \mathrm{yr}$ & (3 d-60 yr) \\
\hline *Valve size & $17.3 \pm 4.4 \mathrm{~mm}$ & $18 \mathrm{~mm}$ & $(9-29 \mathrm{~mm})$ \\
\hline tWarm ischemic time & $4.4 \pm 4.6 \mathrm{hr}$ & $2.5 \mathrm{hr}$ & (0-18.5 hr) \\
\hline$\ddagger$ Cold ischemic time & $2.7 \pm 4.9 \mathrm{hr}$ & $1 \mathrm{hr}$ & $(1-37 \mathrm{hr})$ \\
\hline$\S$ §ntibiotic preservation time & $32.4 \pm 10.5 \mathrm{hr}$ & $30.3 \mathrm{hr}$ & $(12-72 \mathrm{hr})$ \\
\hline
\end{tabular}

*Internal diameter at the annulus.

†Time from heart cessation to end of harvest.

$\ddagger$ Time from end of harvest to start of antibiotic preservation.

$\S$ Time of treatment in antibiotics and Hank's solution at $4^{\circ} \mathrm{C}$.

throughout the study except for the antibiotic preservation time (retrieval to preservation time), which was increased to a minimum of 24 hours in 1996 on the basis of our previous findings. ${ }^{6}$

All homograft data were prospectively collected. Details of preservation and ischemic times were collected on all the valves. Ninety-six valves were harvested from 80 donors. Three valves were purchased elsewhere ( 2 of which lacked preservation data). HLA status was available for 52 of the 96 valves (Table 2).

\section{Tissue Typing}

Tissue typing was performed by the National Institutes of Health technique. Briefly, T lymphocytes were incubated at room temperature for 30 minutes with anti-HLA sera in a 72-well microtray (Biotest AG, Dreieich, Germany). Rabbit complement (Biotest AG) was added, and the tray was incubated for a further 60 minutes at room temperature. Eosin (vital stain) and formaldehyde (fixative) were added, and the reactions visualized with an inverted phase microscope.

For HLA-DR, DNA was extracted by means of a salting-out technique and added to a commercial sequence-specific primer typing tray (GenoVision AS, Oslo, Norway) along with the appropriate thermostable enzyme and buffer. After 10 cycles $\left(94^{\circ} \mathrm{C}\right.$ for 10 seconds, $65^{\circ} \mathrm{C}$ for 60 seconds) on a PE 9700 thermocycler (Perkin Elmer, Norwalk, Conn), the reaction products were visualized by ethidium bromide staining on an agarose gel.

From 1990 to 1995, tissue typing was available for 15 of the 48 valves. Since 1996, donors and recipients of all homografts harvested have been routinely tissue typed. Tissue typing was available for 52 of the valves and 47 of the recipients. HLA-DR match was defined as both loci matched (2/2) or a homozygous donor matching 1 of the recipient alleles.

\section{Operative Technique}

All valves were implanted by 1 of 2 surgeons. The operations were performed through a median sternotomy with standard cardiopulmonary bypass techniques and mild hypothermia $\left(32^{\circ} \mathrm{C}\right)$. The aortic root was not routinely cross-clamped unless other procedures, such as ventricular septal defect closure or an autograft, were required. In 12 patients, the reconstruction involved implant- 


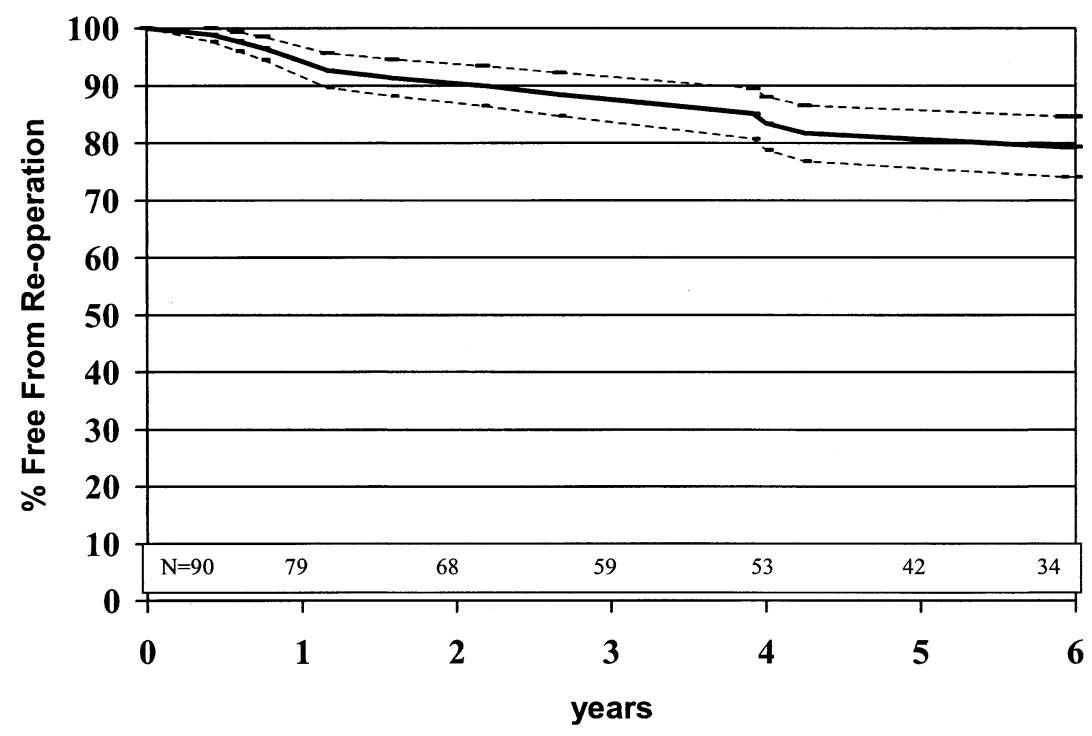

Figure 1. Kaplan-Meier curve of freedom from reoperation for homograft valve failure for the 90 operative survivors. The number of patients at risk is given above the horizontal axis. Freedom from reoperation is expressed as a percentage with $95 \%$ confidence intervals (Cls).

TABLE 3. Risk factors for reoperation for homograft failure

\begin{tabular}{llc}
\hline Covariates & Bivariate & $\begin{array}{c}\text { Multivariate } \\
\text { hazard ratio } \\
\mathbf{( 9 5 \% ~ C l )}\end{array}$ \\
\hline Valve type (pulmonary vs aortic) & $P=.006$ & $0.10(0.04-0.40)$ \\
Antibiotic preservation time & $P=.03$ & $0.90(0.80-0.95)$ \\
Patient age & $P=.008$ & $\mathrm{NS}$ \\
Donor age & $P=.004$ & $\mathrm{NS}$ \\
Weight & $P=.002$ & $\mathrm{NS}$ \\
Valve size & $P=.001$ & $\mathrm{NS}$ \\
Peripheral pulmonary stenosis & $P=.05$ & $\mathrm{NS}$ \\
\hline
\end{tabular}

$\mathrm{Cl}$, Confidence interval; NS, not significant.

ing the homograft as a bifurcated graft. Proximal extensions of autologous pericardium or homograft material were added in 38 patients. Four patients had proximal Dacron (Dupont, Wilmington, Del) polyester fiber extensions. Valve size was determined intraoperatively. We always attempted to insert the largest possible valve. In all cases, the valve was larger than the minimally acceptable pulmonary annulus diameter, as previously published. ${ }^{18}$ Pulmonary valves were used preferentially throughout the period; since 1996, attempts have been made to match for blood type.

\section{Follow-up}

All patients were followed by the cardiology clinic; no patients were lost to follow-up. Patients were seen routinely at 1 to 2 months postoperatively and then every 3 to 6 months or yearly, as dictated by the clinical condition. The guidelines for reporting morbidity and mortality after cardiac valvular operations were followed for the reporting of outcomes. ${ }^{19}$

\section{Echocardiographic Evaluation}

All patients underwent at least 1 transthoracic echocardiographic study in the immediate postoperative period. They were then reexamined serially every 6 to 12 months. All the studies were performed in a standardized fashion by 1 of 2 echocardiographic nurses. All studies were retrospectively reviewed in a random and blinded fashion by a single pediatric cardiologist; $10 \%$ of these were re-reviewed randomly by the same cardiologist without his knowledge. In addition, a second pediatric cardiologist, also in a random and blinded fashion, reviewed $10 \%$ of the studies. The interobserver and intraobserver variability in scoring was assessed using the kappa coefficient. ${ }^{20}$

Echocardiographic observations were made with short-axis parasternal views. Stenosis was assessed by measuring the peak velocity through the valve with continuous-wave Doppler technique. All studies were assessed for valve insufficiency using a graded semiquantitative score. The severity was graded as 0 (absent), $1+$ (a pinhole jet), $2+$ (a jet of regurgitation approximately $20 \%$ of the valve annulus), $3+$ (a wide-based jet approximately $40 \%$ of the annular width), and $4+$ (a broad jet $>40 \%$ of the annular width). $3,6,21,22$

\section{Statistical Analysis}

Data are presented as mean \pm standard deviation, median, and range. All statistical tests were performed with SAS version 8.1 (SAS Institute, Inc., Cary, NC). Bivariate analysis was performed using 2-sided $t$ tests or the chi-square test and Fischer exact tests. Actuarial estimates of freedom from postoperative events were performed with Kaplan-Meier methods. ${ }^{23}$ Cox proportional hazards regression was used for multivariate analysis. Cox proportional hazards analysis model diagnostics and likelihood ratio tests for goodness of fit were performed. Hazard ratios and $95 \%$ confidence intervals (CIs) were estimated from these models. ${ }^{24}$ 


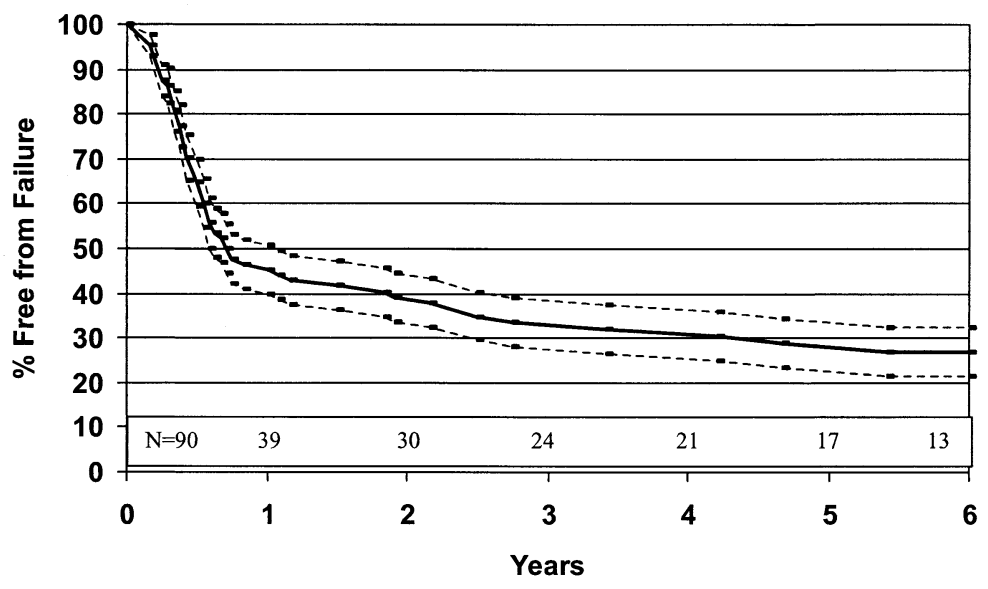

Figure 2. Kaplan-Meier curve of freedom from echocardiographic failure for the $\mathbf{9 0}$ operative survivors (echocardiographic valve failure was defined as a progression of $\geq 2$ grades of insufficiency or a peak transvalvular gradient $\geq 50 \mathrm{~mm} \mathrm{Hg}$ ). The number of patients at risk is given above the horizontal axis. Freedom from echocardiographic failure is expressed as a percentage with $95 \%$ Cls.

The outcomes analyzed were death, reoperation for valve failure, and echocardiographic valve failure. Reoperation was undertaken for pulmonary insufficiency associated with right ventricular dysfunction and dilatation or gradients exceeding 70 to $80 \mathrm{~mm} \mathrm{Hg}$. Echocardiographic valve failure was defined as a progression of 2 or more grades of insufficiency or a peak transvalvular gradient 50 $\mathrm{mm} \mathrm{Hg}$ or more.

Potential variables evaluated in the multivariable analysis included the following: The patient factors were age, sex, weight, diagnosis, peripheral pulmonary stenosis, and redo homograft. The homograft factors were valve type (aortic/pulmonic), valve size, donor age, donor sex, warm ischemic time, cold ischemic time, antibiotic preservation time, blood group mismatch, and HLA-DR mismatch $(2 / 2=$ no mismatch, $0 / 2$ and $1 / 2=$ mismatch $)($ Table 2$)$.

\section{Results}

There were 6 early postoperative deaths, 5 in neonates with truncus arteriosus and 1 in a patient with pulmonary atresia. One late death as the result of pulmonary embolus occurred 2 months after a second homograft replacement in a patient with double outlet right ventricle. No patients were lost to follow-up. Patients were followed for a mean of $55 \pm 35$ months (median 56 months, range 2-142 months). Actuarial survival was $92 \%$ at 10 years (95\%, CI 89\%-95\%).

\section{Reoperation}

Eighteen valves were replaced as the result of pulmonary insufficiency $(n=3)$ or stenosis $(n=9)$ or both $(n=6)$. Freedom from reoperation for homograft valve failure was $71 \%$ at 7 years $(95 \%$ CI $64 \%-77 \%)$ (Figure 1). The mean time to reoperation was $42.6 \pm 33.6$ months (median 39.5, range 5-127 months). There were no deaths at reoperation; 15 patients underwent replacement with a second or third homograft, and 3 patients had a bioprosthetic valve inserted.
In the bivariate analysis, several factors were found to be associated with reoperation (Table 3). In the forward stepwise Cox regression analysis, only 2 variables, homograft type (aortic) and shorter time of antibiotic preservation, were associated with the need for reoperation for valve failure.

\section{Echocardiographic Results}

Postoperative echocardiograms were obtained for all survivors at a mean of $8.2 \pm 9.2$ days (median 7 days, range 1-41 days). At this first echocardiographic evaluation, no patients had greater than $1+$ insufficiency or gradients greater than $15 \mathrm{~mm} \mathrm{Hg}$. A total of 523 studies were reviewed by the primary cardiologist, $10 \%$ of which were re-reviewed at random by the same observer and $10 \%$ by the second cardiologist.

The kappa coefficients for interobserver agreement for the assessment of pulmonary insufficiency were 0.73 and 0.70 for peak gradient, both indicating substantial agreement. ${ }^{20}$ The intraobserver agreement was better with coefficients of 0.80 and 0.78 , respectively.

\section{Echocardiographic Valve Failure}

Sixty of 90 valves failed by our echocardiographic criteria; 48 valves developed progressive insufficiency of 2 or more grades, and 26 homografts developed transvalvular gradients $50 \mathrm{~mm} \mathrm{Hg}$ or greater (14 of these valves also had $\geq 2$ grades of insufficiency). The freedom from echocardiographic valve failure (progression of $\geq 2$ grades of insufficiency or $\geq 50 \mathrm{~mm} \mathrm{Hg}$ gradient or both) was $27 \%$ at 5 years (95\% CI, 17\%-37\%) (Figure 2). The mean time to echocardiographic failure was $11.2 \pm 13.5$ months (median 6 , range 

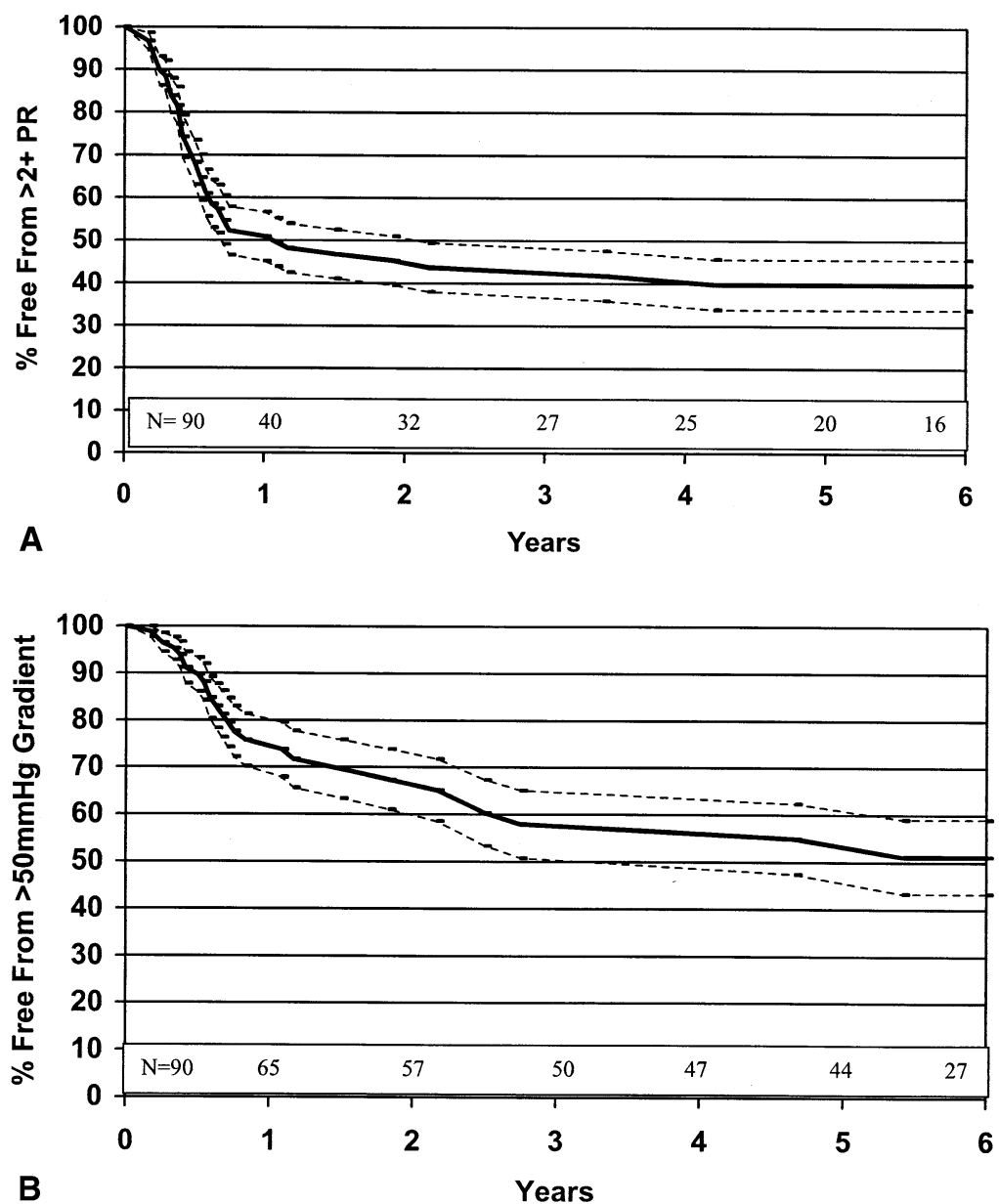

Figure 3. Kaplan-Meier curve of freedom from echocardiographic failure for the 90 operative survivors. A, A progression of 2 or more grades of insufficiency. B, A peak transvalvular gradient $50 \mathrm{~mm} \mathrm{Hg}$ or greater. The number of patients at risk is given above the horizontal axis. Freedom from echocardiographic failure is expressed as a percentage with $95 \%$ Cls (log-rank test $P=.01)$.

TABLE 4. Risk factors for homograft valve failure

\begin{tabular}{llc}
\hline Covariates & Bivariate & $\begin{array}{c}\text { Multivariate } \\
\text { hazard ratio } \\
\mathbf{( 9 5 \% ~ C I )}\end{array}$ \\
\hline Patient age & $P<.0001$ & $0.98(0.96-0.99)$ \\
ABO match & $P=.01$ & $0.51(0.27-0.96)$ \\
Diagnosis (pulmonary atresia) & $P=.27$ & $2.53(1.1-12.2)$ \\
Donor age & $P=.001$ & $\mathrm{NS}$ \\
Weight & $P=.001$ & $\mathrm{NS}$ \\
Valve size & $P=.001$ & $\mathrm{NS}$ \\
\hline
\end{tabular}

3-65). Patients who developed valve failure had a nonstatistically significant shorter follow-up, with a mean of $50 \pm 30$ months (median 49 months, range 3-113 months), than those who did not develop homograft failure, with a mean of $67 \pm 42$ months (median 71, range 2-142 months; $P=.07$ ).
Comparison of valve failure from insufficiency and stenosis shows that insufficiency was more common and developed much more rapidly than from stenosis (Figure 3). The freedom from progression of homograft insufficiency of 2 or more grades was $40 \%$ at 4 years $(95 \%$ CI, 34\%$46 \%$ ), and the freedom from stenosis of $50 \mathrm{~mm} \mathrm{Hg}$ or greater was $58 \%$ at 4 years $(95 \%$ CI, 51\%-65\%; log-rank test $P=.001)$. The mean time to failure from insufficiency was $8.5 \pm 10.1$ months (median 6 months, range 2-50 months). In contrast, the mean time to failure from stenosis was $19.7 \pm 18.6$ months (median 13 months, range 2-65 months; $P=.03$ ).

In the bivariate analysis, several factors were associated with failure. In the multivariate analysis of echocardiographic homograft valve failure, only younger age at operation, blood group mismatch, and the diagnosis of pulmonary atresia were associated with valve failure (Table 4). 
In separate bivariate analyses of failure caused by insufficiency or stenosis alone, blood group mismatch, age, weight, and valve size were significantly associated with failure caused by insufficiency, whereas only valve type (aortic) was significantly associated with failure caused by stenosis. In the multivariate analysis of failure caused by insufficiency, there was a nonsignificant trend toward age, valve type, and $\mathrm{ABO}$ mismatch being associated with failure.

\section{HLA Analysis}

A subanalysis was conducted of valves for which tissue typing was available for both the donor and the recipient (n $=47$ ), with echocardiographic valve failure as the outcome. Eighteen of 27 HLA-DR mismatched patients developed echocardiographic valve failure compared with 8 of 20 matched patients $(P=.07)$. The 5-year freedom from echocardiographic homograft valve failure for matched and unmatched patients was $49 \%$ versus $33 \%$ (log-rank test $P=$ .67). In the bivariate analysis, only blood group mismatch was significantly associated with echocardiographic failure. However, in the multivariate analysis, younger age, valve type (aortic), and complete HLA-DR mismatch were associated with valve failure (Table 5).

\section{Discussion}

We demonstrated for the first time that homograft valve failure in children is associated with HLA-DR mismatch. Furthermore, there is a consistent association between various factors in homograft procurement and preservation that is known to preserve immunogenicity and homograft failure. Specifically, blood group mismatch, short antibiotic preservation time, and valve type (aortic) are all associated with homograft valve failure.

In Dignan and colleagues, ${ }^{9}$ study of aortic homografts in adults, there was a bivariate association between HLA-DR mismatch and homograft deterioration in patients followed for more than 5 years. This association did not remain in the multivariate analysis. Their finding of an association between a short time from retrieval to cryopreservation and homograft structural deterioration (defined as a peak gradient $\geq 50 \mathrm{~mm} \mathrm{Hg}$ or 3 and $4+$ insufficiency) confirms our earlier findings in children, ${ }^{6}$ which are also confirmed in the present study. Smith and colleagues' ${ }^{16}$ series of adult noncryopreserved homografts found a nonsignificant trend toward increased valve dysfunction in patients who developed HLA antibodies, but no association between HLA mismatch and valve failure or reoperation. The failure to show a significant effect of HLA matching in adults is likely a reflection of the weaker immune response to homografts seen in adults, the duration of follow-up, and the lower incidence of valve failure in the adult patient.
TABLE 5. Risk factors for homograft valve failure (subset with tissue typing, $n=47$ )

\begin{tabular}{lcc}
\hline Covariates & Bivariate & $\begin{array}{c}\text { Multivariate } \\
\text { hazard ratio } \\
(\mathbf{9 5 \%} \mathrm{Cl})\end{array}$ \\
\hline HLA-DR match & $P=.07$ & $0.10(0.01-0.94)$ \\
Age (mo) & $P=.16$ & $0.88(0.82-0.95)$ \\
Valve type (pulmonary vs & $P=.08$ & $0.20(0.02-0.89)$ \\
$\quad$ aortic) & $P=.03$ & $\mathrm{NS}$ \\
ABO match & & \\
\hline
\end{tabular}

HLA, Human Leukocyte antigen; $H R$, hazard ratio.

It is clear that children and adults respond differently to homografts. Virtually all studies have found younger age to be a predictor of early failure. ${ }^{3,5,6,9} \mathrm{~A}$ donor-specific antibody response is induced by homograft implantation. ${ }^{7,10,15}$ There is evidence that children produce a virulent $\mathrm{T}$-cell response, whereas adults mount a much weaker response. ${ }^{8}$ In addition, laboratory studies have demonstrated that allograft valve destruction is T-cell mediated. ${ }^{25}$

This current study is limited by the small number of patients, particularly the subanalysis of the HLA-typed patients. However, this is one of the largest series with such detailed follow-up. There is consistency of the results among the different analyses, and the variables identified are consistent with the results of other studies. ${ }^{3,8,9}$ It is likely that the other HLA loci and nonimmunologic factors, including growth, degeneration, and technique, play a role in homograft failure. ${ }^{14}$ However, the timing of the failure is more consistent with rejection.

An important advantage of our serial echocardiographic follow-up (every 6-12 months) is that the time to failure can be accurately identified. An observation arising from this is that the failure, particularly resulting from insufficiency, occurs quite early (Figure 3).

There are promising new technologies attempting to reduce or eliminate the antigenicity of homografts. ${ }^{26-28}$ At present, homografts seem to still be the best option for right ventricular outflow tract reconstruction in children. ${ }^{29,30}$ Some clinical efforts have been made for the use of immunosuppression, but there is no evidence that this works. Laboratory studies indicate that long-term rather than shortterm immunosuppression would be required. ${ }^{25}$ Despite this, some groups advocate routine immunosuppression in younger patients. ${ }^{31}$

The present state of knowledge does not seem to warrant routine immunosuppression. However, there is good evidence that ensuring valves are matched for HLA-DR and blood group, and that storage and procurement times are optimized, may delay valve failure with little or no risk to the recipient.

In summary, we have found that several important factors in homograft preservation and selection are associated 
with failure of the valves. Several of these, including valve type, preservation times, blood type, and HLA-DR mismatch, are modifiable and thus can be used to improve clinical results.

\section{References}

1. Doty J, Salazar J, Liddicoat J, Flores J, Doty D. Aortic valve replacement with the cryopreserved aortic allograft: ten-year experience. J Thorac Cardiovasc Surg. 1998;115:371-80.

2. McGiffin D, Galbraith A, O'Brien M, et al. An analysis of valve re-replacement after aortic valve replacement with biological devices. J Thorac Cardiovasc Surg. 1997;113:311-8.

3. Niwaya K, Knott-Craig C, Lane M, Chandrasekaren K, Overholt E, Elkins R. Cryopreserved homograft valves in the pulmonary position: risk analysis for intermediate-term failure. J Thorac Cardiovasc Surg. 1999;117:141-7.

4. Briand M, Pibarot P, Dumesnil J, Cartier P. Midterm echocardiographic follow-up after Ross operation. Circulation. 2000;102(suppl III): $10-4$

5. Clarke D, Campbell D, Hayward A, Bishop D. Degeneration of aortic valve allografts in young recipients. J Thorac Cardiovasc Surg. 1993; 105:934-42.

6. Baskett R, Ross D, Nanton M, Murphy D. Factors in the early failure of cryopreserved homograft pulmonary valves in children: preserved immunogenicity? J Thorac Cardiovasc Surg. 1996;112:1170-9.

7. Hogan P, Duplock L, Green M, et al. Human aortic valve allografts elicit a donor-specific immune response. J Thorac Cardiovasc Surg. 1996;112:1260-7.

8. Vogt P, Stallmach T, Niederhauser U, et al. Explanted cryopreserved allografts: a morphological and immunohistochemical comparison between arterial allografts and allograft heart valves in infants and adults. Eur J Cardiothorac Surg. 1999;15:639-45.

9. Dignan R, O'Brien M, Hogan P, et al. Influence of HLA matching and associated factors on aortic valve homograft function. J Heart Valve Dis. 2000;9:504-11.

10. Smith J, Ogino H, Hunt D, Laylor R, Rose M, Yacoub M. Humoral immune response to human aortic valve homografts. Ann Thorac Surg. 1995;60:S127-30.

11. Rajani B, Mee R, Ratliff N. Evidence for rejection of homograft cardiac valves in infants. $J$ Thorac Cardiovasc Surg. 1998;115:111-7.

12. Hoekstra F, Knoop C, Jutte N, et al. Effect of cryopreservation and HLA-DR matching on the cellular immunogenicity of human cardiac valve allografts. J Heart Lung Transplant. 1993;13:1095-8.

13. Hoekstra F, Knoop C, Zohara A, et al. Stimulation of immunecompetent cells in vitro by human cardiac valve-derived endothelial cells. Ann Thorac Surg. 1995;60:S131-4.

14. Hawkins J, Breinholt J, Lambert L, et al. Class I and class II anti-HLA antibodies after implantation of cryopreserved allograft material in pediatric patients. J Thorac Cardiovasc Surg. 2000;119:324-30.

15. Hoekstra F, Witvliet M, Knoop C, et al. Immunogenic human leukocyte antigen class II antigens on human cardiac valves induce specific alloantibodies. Ann Thorac Surg. 1998;66:2022-6.

16. Smith J, Hornick P, Rasmi N, Rose M, Yacoub M. Effect of HLA mismatching and antibody status on "homovital" aortic valve homograft performance. Ann Thorac Surg. 1998;66:S212-5.

17. Bechtel J, Bartels C, Schmidtke C, et al. Does histocompatibility affect homograft valve function after the Ross procedure? Circulation. 2001; 104(suppl I):25-8.

18. Pacifico A, Kirklin J, Blackstone E. Surgical management of pulmonary stenosis in tetralogy of Fallot. J Thorac Cardiovasc Surg. 1977; 74:382-95.

19. Edmunds L, Clark R, Cohn L, Grunkemeier G, Miller D, Weisel R. Guidelines for reporting morbidity and mortality after cardiac valvular operations. J Thorac Cardiovasc Surg. 1998;112:708-11.

20. Landis J, Koch G. The measurement of observer agreement for categorical data. Biometrics. 1977;33:159-74.

21. Chan K, Fyfe D, McKay C, Sade R, Crawford F. Right ventricular outflow tract reconstruction with cryopreserved homografts in pediat- ric patients: intermediate-term follow-up with serial echocardiographic assessment. J Am Coll Cardiol. 1993;24:483-9.

22. Bando K, Danielson G, Schaff H, Mair D, Julsrud P, Puga F. Outcomes of pulmonary and aortic homografts for right ventricular outflow tract reconstruction. J Thorac Cardiovasc Surg. 1995;109:50918.

23. Kaplan E, Meier P. Nonparametric estimation from incomplete observations. J Am Stat Assoc. 1958;53:457-81.

24. Cox D. Regression models and life tables. J R Stat Soc Br. 1972;34: 187-220.

25. Legare J, Ross D, Issekutz T, et al. Prevention of allograft heart valve failure in a rat model. J Thorac Cardiovasc Surg. 2001;122:310-7.

26. Elkins R, Dawson P, Goldstein S, Walsh S, Black K. Decellularized human valve allografts. Ann Thorac Surg. 2001;71:S428-32.

27. Messier R, Bass B, Domkowski P, Hopkins R. Interstitial cellular and matrix restoration of cardiac valves after cryopreservation. $J$ Thorac Cardiovasc Surg. 1999;118:36-49.

28. Steinhoff G, Stock U, Karim N, et al. Tissue engineering of pulmonary heart valves on allogenic acellular matrix conduits: in vivo restoration of valve tissue. Circulation. 2000;102(suppl III):50-5.

29. Caldarone C, McCrindle B, Van Arsdell G, et al. Independent factors associated with longevity of prosthetic pulmonary valves and valved conduits. J Thorac Cardiovasc Surg. 2000;120:1022-31.

30. Levine A, Miller P, Stumper O, et al. Early results of right ventricularpulmonary artery conduits in patients under 1 year of age. Eur J Cardiothorac Surg. 2001;19:122-6.

31. Al-Halees Z, Pieters F, Qadoura F, Shahid M, Al-Amri M, Al-Fadley F. The Ross procedure is the procedure of choice for congenital aortic valve disease. J Thorac Cardiovasc Surg. 2002;123:437-42.

\section{Discussion}

Dr David R. Clarke (Denver, Colo). Congratulations to Dr Baskett and his coauthors are certainly in order for an excellent clinical study and presentation.

This study clearly puts yet another nail in the coffin of the theory that cryopreserved allografts do not elicit an immune response. It also goes further and irrefutably links ABO and HLA incompatibility to graft failure determined by the need for reoperation or echocardiographic evidence of progressive regurgitation or significant stenosis. Two other risk factors identified could also be associated with an immune phenomenon: Use of an aortic homograft and shorter warm ischemic time could presumably lead to the implantation of a higher antigenic load. Are there other possible explanations for the appearance of these risk factors?

Dr Baskett. It is a hard group of patients to look at, as I know you are well aware. There is so much we do not know about how the preservation affects the valves. I think some of the clinical factors, such as the diagnosis of pulmonary atresia, which often goes along with peripheral pulmonary stenosis, probably unmask failure sooner than you may see in a patient, for example, with a Ross procedure (in which there is not the same need for a competent valve). But as you point out, there seems to be a consistent association among several factors that are known to increase the antigenic load and valve failure. This seems to keep coming through in everybody's work.

Dr Clarke. You also have identified age at operation as a risk factor that has been identified in previous studies. In previous studies, it seems that stenosis in younger patients was very common. Did you find a difference in the failure mode related to the age of the patient at implantation?

Dr Baskett. That is a very good question. We did not look specifically at that when we were constructing our statistical models. The different variables presented and how one chooses to 